УДК 37

DOI $10.21661 / r-497855$

\title{
Т.В. Алексеева
}

\section{ОСОБЕННОСТИ СОВРЕМЕННЫХ ИНТЕРНЕТ-СМИ КАК СОДЕРЖАТЕЛЬНЫЙ КОМПОНЕНТ ОБУЧЕНИЯ}

Аннотация: статья посвящена отбору и обновлению содержания обучения будущих специалистов медиаиндустрии. Поскольку стремительная трансформация традиционных медиа диктует необходимость уточнения и модернизации конщепџий медиаиндустрии, то обновление содержательного компонента обучения является приоритетным направлением педагогической деятельности. Анализируя процессы развития СМИ, автор статьи исследует ряд специфических особенностей, лежащих в основе принципов функиионирования интернет-СМИ; рассматривает концепџию взаимодействия интернетСМИ с современным потребителем; структурные и технологические трансформации, влияющие на принципы создания контента и сопряженные с монетизачией. Рассмотренные в статье вопросы позволят участникам процесса обучения разобраться в многоаспектности современных СМИ и наметить ориентиры дальнейших исследований.

Ключевые слова: содержательный компонент обучения, обновление содержания обучения, подготовка специалиста медиаиндустрии, СМИ, цифровая трансформачия, медиаиндустрия, медиапотребление, особенности интернет-СМИ.

\section{T.V. Alekseeva}

\section{FEATURES OF MODERN INTERNET MEDIA AS A SUBSTANTIVE COMPONENT OF TRAINING}

Abstract: the article is devoted to the selection and updating of the training content of future media industry specialists. Since the rapid transformation of traditional media dictates the need to clarify and modernize the concepts of the media industry, updating of the substantive component of training is a priority for educational activi- 
ties. Analyzing the processes of mass media development, the author considers a number of specific features underlying the principles of online media functioning; explores the concept of interaction between online media and the modern consumer; structural and technological transformations affecting the principles of content creation and associated with monetization. The questions discussed in the article will allow participants in the learning process to understand the multidimensionality of the modern mass media and to set guidelines for further research.

Keywords: the substantive component of training, the updating of the training content, the training of a media industry specialist, mass media, digital transformation, the media industry, media consumption, internet media features.

В соответствии с современными требованиями, предъявляемыми к качеству образования, содержательный компонент учебного процесса подготовки специалиста медиаиндустрии подлежит постоянному обновлению, отражающему протекающие изменения в реальной действительности будущей профессиональной сферы деятельности обучающегося. В этой связи педагогу необходимо проводить исследования и анализ развития медиаиндустрии, для ориентации в постоянно меняющейся действительности и возможности обновления содержания обучения по преподаваемой дисциплине.

Цифровая трансформация и упрочение сетевых СМИ на медиарынке привели к изменению традиционного представления о контенте как об информационном сообщении, не имеющим аналогов. Согласно данным опросов Фонда общественного мнения [https://fom.ru] в 2019 году 44\% населения узнают о новостях из сетевых источников, ядром целевой аудитории интернет-СМИ являются люди с высшим образованием (59\%) в возрасте от 18 до 60 лет. Специфические особенности современных медиа предоставляют новые возможности взаимодействия с современным потребителем, причем являясь сдвоенным рынком товаров и услуг, интернет-СМИ должны осуществлять эффективную деятельность, с одной стороны, для привлечения рекламодателей, а с другой, 
для максимизации аудитории. Актуальность данного вопроса обусловлена повышающимся уровнем востребованности интернет-СМИ у потребителя.

Редакции первых интернет-СМИ, которые появились в 1999 году, самостоятельно разрабатывали принципы функционирования и способы монетизации, основываясь на практическом опыте. Спустя 19 лет эта область остается малоизученной, а теоретическая база, включающая в себя структурные особенности и эффективные бизнес-концепции, нуждается в значительном расширении исследовательского горизонта. В связи с этим существует потребность в изучении вопросов функционирования современного сетевого СМИ.

Ведущими теоретика в области исследований современной журналистики, занимающимися изучением сетевых СМИ как феноменом массовых коммуникаций со структурной и экономической точек зрения, являются такие ученые, как: Е.Л. Вартанова, Е.П. Прохоров, Г.М. Маклюэн, Я.Н. Засурский, М. Кастельс, Р.П. Овсепян, С.М. Гуревич, А.А. Калмыков, В.Л. Иваницкий, С.И. Сметанина, А.Г. Качкаева, С.Г. Машкова и др. Фундаментальные исследования, включающие в себя попытку структурировать и типологизировать сетевые СМИ, принадлежат М.М. Лукиной и И.Д. Фомичевой. Следует отметить, что используемые такие понятия как «сетевые СМИ», «онлайн-СМИ», «интернет-СМИ», «интернет-медиа», «новые медиа» и «современные медиа» являются тождественными.

За последние 50 лет система средств массовой информации претерпела ряд структурных изменений. Всемирная информационная компьютерная сеть, начало становления которой относится к 1969 году, уже через 21 год стала основой для развития абсолютно новой формы коммуникации - интернет-СМИ. Первая сетевая газета «The Electronic Trib», не имевшая печатной версии, появилась в 1990 году [1]. На тот момент Советский Союз впервые присоединился к глобальной сети Интернет. В 1992 году новое пространство использовалось в качестве распространения электронных версий газеты «Известия», до 1995 года широкое распространение получили индивидуальные авторские проекты, созданные без участия юридических лиц. В этот период в сети Интернет были 
запущены такие проекты, как «Вечерний Интернет», «Паравозов-News», представляющие собой новый жанр - «сетевое обозрение» [2].

Тогда сетевые СМИ в общественном сознании не рассматривались в качестве средства получения информации наравне с традиционными формами. Кризис 1998 года кардинально изменил эту ситуацию, когда в контексте абсолютного информационного вакуума, люди обратились к сетевым СМИ, как к источнику оперативного новостного контента [3]. Тогда же в августе, когда многие традиционные издания закрывались, интернет-СМИ значительно расширили свою аудиторию, что позволило говорить о сетевых СМИ как о принципиально новой форме коммуникации. Это, в свою очередь, создало необходимость формирования, с одной стороны, других структурных систем, с другой, современных бизнес-моделей, позволяющих монетизировать контент.

Интернет-СМИ отличают ряд специфических особенностей, дающих другие возможности взаимодействия с современным потребителем, среди которых мультимедийность и гипертекстуальность, обеспечивающие новые возможности в получения и потребления информации. Еще одна особенность, дающая возможность многостороннего обмена информацией, - интерактивность, которая позволяет максимально усилить не только обратную связь, но и вовлечь пользователя в процесс создания контента. Главное преимущество интернетСМИ перед традиционными медиа обеспечивает такая особенность, как оперативность. Известно, что из скорости публикации новостных сообщений, в свою очередь, складывается индекс цитируемости, показатели которого напрямую влияют на количество рекламодателей, и, как следствие, на экономику интернет-СМИ. При этом для сетевых СМИ в силу физической среды существования отсутствуют территориальные границы распространения, что позволяет говорить о максимально широкой потенциальной аудитории, которой нет ни у одного другого традиционного СМИ.

Технические особенности интернет-СМИ обеспечивают возможность персонифицированного (индивидуального) подхода взаимодействия с современным потребителем. Исходя из анализа целевой аудитории, а именно, основыва- 
ясь на предыдущих поисковых запросах, существует возможность отправки индивидуальных push-уведомлений, а также изменение и настройка графического оформления, учитывая интересы каждого пользователя. Простота измеримости целевой аудитории интернет-СМИ является преимуществом в коммуникативном вопросе с рекламодателем - предоставление точных сведений о составе целевой аудитории упрощается благодаря цифровому анализу сетевого медиа.

Учитывая относительную новизну направления и его стремительное развитие, интернет-СМИ не имеют четкой классификации. Все современные медиа, существующие в сети неоднородны по своей структуре, различны по формату и находятся в постоянной эволюции. Существовавшая на сегодняшний день тенденция медиапотребления - пассивная модель сменяется активной, когда человек максимально вовлечен в процесс, а область его интересов обеспечивается интерактивными формами и снабжается персонифицированной информацией. Бесспорно, что появление информационно-коммуникативных технологий является началом изменений принципов работы всей системы СМИ. Структурные изменения современных медиа основываются на двух технологических процессах. Первым из них является дигитализация, или преобразование контента (текст, графическое и звуковое оформление) в цифровой формат. Это снимает пространственные и экономические ограничения, существующие для традиционных СМИ. Вторым процессом, лежащим в основе структурных изменений, является конвергенция. Это явление оказывает большое влияние на традиционный сектор медиаэкономики. По мнению исследователей, именно конвергенция способна в ближайшие 10 лет модифицировать рынок СМИ [4].

Сетевые СМИ - многоуровневый механизм, интегрирующий все средства массовой коммуникации. Виртуальность новой формы медиа приводит к структурной трансформации и изменению функций, сложившихся в системе СМИ [5]. На первый взгляд, производственные процессы традиционных СМИ и новых медиа одинаковы: поиск информации - упаковка - распространение. Рассматривая эти процессы изнутри, очевидным становится тот факт, что принципы создания контента в новых медиа имеют ряд принципиальных отли- 
чий. Для интернет-пользователя важными аспектами потребляемого контента являются скорость его подачи и мультимедийность упаковки (разнообразие используемых форм подачи информации - текст, аудио, фото, видео). В связи с этим появился смешанный вид структурного функционирования редакции: одна часть сотрудников добывает информацию, при этом упаковывает ее самостоятельно сразу в нескольких форматах. В зависимости от ресурсов интернетСМИ этот процесс может быть разделен на два этапа: журналист добывает информацию, поставляя ее в редакцию, а тематический отдел занимается ее упаковкой. Вторая часть редакции отбирает из общего потока важные информационные поводы, являясь так называемым агрегатором, перерабатывает текст, дополняет его аудиовизуальным контентом.

Цифровой способ передачи и распространения информационных потоков стал определяющим фактором возникновения абсолютно новой структурной модели СМИ - краудсорсинга - системы обмена и управления информацией, которая предполагает использование ресурсов сетевого общества. Для интернет-СМИ такая модель обеспечивает максимальную вовлеченность аудитории в процесс создания контента.

Существует и принципиально новый способ создания контента для сетевых СМИ, в корне меняющий представление о традиционной редакции - искусственный интеллект. Программа-робот впервые была протестирована и запущена в рамках Олимпийских игр в Рио-де-Жанейро в 2016 году. В функции ботов входит оперативный поиск, генерация и публикация материалов. Принцип работы таких программ заключается в поиске информации по ключевым словам; семантическом и синтаксическом анализе текста, на основании чего осуществляется выделение главной и второстепенной информации; формировании базы данных и структурировании слов в предложения. Основным преимуществом внедрения искусственного интеллекта в редакционный процесс является сокращение времени на подготовку материала - бот осуществляет оперативный поиск и обработку информации, исключая при этом ошибки журналиста, обусловленные человеческим фактором. 
Вопрос развития взаимодействия СМИ с современным потребителем тесно связан с экономической моделью функционирования интернет-СМИ [6]. В условиях существования рыночных отношений вектор развития сферы медиа во многом определяет экономический аспект. Сетевые СМИ являются отраслью информационной экономики. Если в индустриальной экономике основными показателями является количество производимого продукта, которое находится под контролем производителя, то в информационной экономике главную позицию занимает качество продукта, а его направленность регулируется потребителем. Несмотря на новизну этого направления, монетизацию контента в сети необходимо рассматривать в контексте традиционного экономического сектора. Как и любое традиционное СМИ (радио, телевидение, печать) сетевые медиа представляют собой сдвоенный рынок товаров и услуг - в качестве товара выступает и контент для пользователей, и аудитория для рекламодателя.

Взаимодействие интернет-СМИ с современным потребителем связано с таким важным экономическим аспектом, как монетизация. Существуют разные модели монетизации. Монетизация посредством продажи доступа к трафику - модель, построенная на получении дохода от продажи рекламы. Модель монетизации посредством продажи доступа к контенту подразумевает платную подписку. Также в функционировании интернет-СМИ активно применяется смешанный вид, когда часть информации предоставляется на бесплатной основе, а вторая - специализированная - на платной. И еще одна, краундфаундинговая модель, согласно которой финансирование интернет-СМИ складывается из добровольных пожертвований читателей. Следует отметить, что на российском медиарынке преобладает смешанная бизнес-концепция монетизации контента с преобладанием продажи доступа к трафику.

Таким образом, на ряду с традиционными СМИ, которые на сегодняшний день остаются главными источниками информации, стремительно растет доверие аудитории к интернет-СМИ. В связи с этим возникает необходимость в исследовании процесса формирования сетевых СМИ как новой формы коммуникации в информационном обществе, а также в изучении структурных особенно- 
стей интернет-СМИ, анализе реорганизаций традиционных редакционных процессов, в т.ч. конвергенции. При этом для успешного экономического функционирования интернет-СМИ важным является создание качественного контент и его последующее продвижение, поскольку качественный контент и его грамотное продвижение способно привлечь аудиторию, а её отклик - рекламодателя. Изучение этих вопросов позволит педагогу, преподающему аспекты интернетСМИ, логично и грамотно выстроить обновленное содержание обучения.

\section{Сиисок литературы}

1. Баранова Е.А. Конвергентная журналистика. Теория и практика: учеб. пособие для бакалавриата и магистратуры. - М., 2014. - 269 с.

2. Белоусова М.Н. Создание мультимедийного контента - особый вид деятельности журналиста / М.Н. Белоусова, А.Н. Широбоков // Вестник Челябинского государственного университета. - 2012. - № 6 (260).

3. Машкова С.Г. Интернет-журналистика: учеб. пособие / С.Г. Машкова. Тамбов: Изд-во Тамб. гос. техн. ун-та, 2006. - 80 с.

4. Качкаева А.Г. Журналистика и конвергенция. Почему и как традиционные СМИ превращаются в мультимедийные / под ред. А.Г. Качкаевой. - М., 2010. -200 c.

5. Интернет-СМИ: Теория и практика: учеб. пособие для студентов вузов / под ред. М.М. Лукиной. - М.: Аспект Пресс, 2010. - 348 с.

6. Шлыкова О.В. Культура мультимедиа. - М., 2004. - 415 с.

\section{References}

1. Baranova, E. A. (2014). Konvergentnaia zhurnalistika. Teoriia i praktika. M.

2. Belousova, M. N., \& Shirobokov, A. N. (2012). Sozdanie mul'timediinogo kontenta. Vestnik Cheliabinskogo gosudarstvennogo universiteta, $6(260)$.

3. Mashkova, S. G. (2006). Internet-zhurnalistika: ucheb. posobie., 80. Tambov: Izd-vo Tamb. gos. tekhn. un-ta. 
4. Kachkaevoi, A. G., \& Kachkaeva, A. G. (2010). Zhurnalistika i konvergentsiia. Pochemu i kak traditsionnye SMI prevrashchaiutsia $\mathrm{v}$ mul'timediinye., 200. M.

5. Lukinoi, M. M. (2010). Internet-SMI: Teoriia i praktika: ucheb. posobie dlia studentov vuzov., 348. M.: Aspekt Press.

6. Shlykova, O. V. (2004). Kul'tura mul'timedia., 415. M.

Алексеева Тамара Валентиновна - канд. пед. наук, декан, доцент кафедры телевидения, ФГБОУ ВО «Санкт-Петербургский государственный институт кино и телевидения», Санкт-Петербург, Россия.

Alekseeva Tamara Valentinovna - candidate of pedagogical sciences, dean, assistant professor of Television Department, FSBEI HE "St. Petersburg State University of Film and Television", Saint Petersburg, Russia. 